\title{
Estudio de un sistema agrario: El distrito de riego y avenamiento de Zapotitán
}

\author{
Cooperación técnica francesa.
}

\section{Introduccion}

Esle articulo reune extractos del informe final de una invesligación llevada a cabo en el Distrilo de Riego y Avenamiento de Zapolitán**

Sus objetivos eran:

- Aplicar a una realidad agraria un método especifico de análisis, el cual fue expuesto en la Revista Realidad Económico-Social No. 2.

- Estudiar las condiciones de aplicación de una alternativa tecnológica, el riego, que parece, a priori, responder a las necesidades de aumentar la producción por manzana, por una reactivación de la economía salvadorefia.

De hecho, el conjunto de las coacciones objetivas que limilan las orientaciones de las acluales y fuluras políticas agrarias salvadorenas implica que de cualquier modo uno de los ejes de acción debe intentar organizar las condiciones tanto técnicas como económicas y sociales, para incrementar el valor agregado y el empleo por manzana, y, en primer lugar, en las lierras irrigables del país, como las de Zapolitán. En este senlido.

- Esta investigación fue desarrollada por los miembros de Cooperación Técnica Francesa: Clement San Sebastian, Jean Marc e Isabelle Touzard, Stephane Canú y Benoit Faivre.

* Ver el informe final de la investigación, en el tilulo: "Diagnóstico sistemático de una realidad agraria; aplicación a una microregión de El Salvador: El Distrito de Riego y Avenamiento de Zapotitán." 2da. perte. Cooperación Técnica Francesa, Departamento de Economla, UCA. San Salvador 1988. 
se vuelve importante a la vez conlar con una metodologia que permita llevar a cabo diagnósticos de pequefías regiones agricolas y sacar conclusiones de la experiencia de esle proyeclo de riego, visla la posible y necesaria extensión de esa técnica a otras zonas del pais.

\section{Caracterlzación y zonlficación agro-ecológlca y soclo- económica de la zona de estudio.}

Nuestra zona de estudio está ubicada al kilómetro 30 de la carretera de San Salvador a Santa Ana y corresponde al "Distrilo de Riego y Avenamiento de Zapotitán" o sea 3900 hectáreas cuyos 3800 son agrícolas; es una depresión con pendientes inferiores a $3 \%$, que pertenece a la cuenca hidrográfica del Rio Sucio: esta zona presenta a la vez una cierta unidad geomortológica y ecológica (el sitio de la antigua laguna de Zapolitán y sus alrededores), histórica (la hacienda de Zapotitán adjudicada por el gobierno de Martinez), y constituye un campo geograficamente definido de acción del estado a través del "Proyecto de desarrollo agrícola del Valle de Zapotitán" y de la ley de creación del distrito.

Siguiendo la metodologia expuesta en "Realidad No. 2" se estudiaron, en una primera elapa, los elementos físicos y socio-económicos que influyen los sistemas de producción, para poder definir subzonas con problemática homogénea: Pues, aunque tenga una área reducida, rechazamos la idea de que el distrilo sea en sí una zona homogénea, lo que nos incita a buscar siempre la variabilidad de los factores escogidos y a jerarquizarlos.

\section{El medio físico}

Los dos principales faclores lísicos que influyen fuertemente las decisiones de los agricultores de Zapolitán son la naturaleza de los suelos y la pluviometría:

1.1.La varlabllldad de los suelos (en sus características hidricas) determina zonas con limitaciones agronómicas muy distintas: por ejemplo, en la parte central y en el silio de la antigua laguna, los suelos hidromorfos impiden todo cullivo de invierno salvo el arroz, mientras que, al sur de la zona, los suelos muy permeables, permiten cultivar maiz en invierno, pero requieren un riego temprano e importanle para los cultivos de verano.

1.2. El régimen de las lluvlas (entre 1400 y $1800 \mathrm{~mm}$ anuales), relativamente variable de un año al otro, impone una limitación general para la zona: la casi imposibilidad de cullivar hortalizas en invierno, por la fragilidad de estas plantas frente a condiciones propicias a las plagas. 


\section{La Intervención humana sobre el medlo natural}

2.1. Las distintas especulaclones agricolas tienen que ser esludiadas en términos de sucesión de cultlvos para conocer la ocupación del suelo al largo de todo el ano, y poder mostrar de manera sintética y precisa su repartición espacial. Los pastos $(10 \%$ del área agrícola), de pastoreo o de corte, y regados en verano, mantienen generalmente a una ganadería de leche. La caña de azúcar ( $20 \%$ del área) se encuentra más que todo en las tierras de mejor drenaje donde alcanza un rendimiento del 100 toneladas métricas/ha. Las rotaclones de granos básicos de Invlerno (arroz en las zonas más humedas, maíz en olras partes) y cultivos regados de verano (hortalizas, tabaco, frijol, maíz,.... ocupan el $67 \%$ del área agrícola: en verano se suceden a menudo dos ciclos de cullivos (por ejemplo frijol-hortaliza); se encuemran barbechos temporarios (3-5 meses) en el seno de estas rotaciones, en invierno para las zonas pantanosas y en verano en todo el distrito (los barbechos de verano son debidos ellos a la imposibilidad temporal o económica de implentar un cultivo adicional, al uso del barbecho como poIreros, a las deficiencias del riego, etc,...). Asi, en lotal, sobre las 2500 ha que incluyen estas rotaciones, se siembran más o, menos 4800 ha en un ano, o sea una tasa de ocupación del suelo de casi dos veces. Por último, frutales (guineos, cílricos, papayos,...), flores, granjas avicolas, y algunos barbechos permanentes ( 50 ha por lo menos) ocupan el resto del área agrícola (3\%).

2.2. El peso económlco de las distintas producclones, en relación con su extensión, nos indica que la cana contribuye solamente a $12-13 \%$ de la producción total del distrito, en términos monetarios (por más de $20 \%$ del área), mientras que la producción lechera $(17 \%$ de la producción lolal) liene la producción por hectárea y por dla-hombre la más alta de la zona, debido a la importancia del trabajo cristalizado. Las rotaciones granos básicos-hortalizas (69\% de la producción monetaria del dislrito) se caraclerizan más que lodo por su absorción fuerte en mano de obra ( $75 \%$ del total).

2.3. El acceso a la tlerra es sumamente desequilibrado: una decena de unidades de administración de más 50 hecláreas ${ }^{1}$ ocupan unos $20 \%$ del área total, mientras que las propiedades de menos de 2 has ( $67 \%$ del tolal) tocan la misma superficie total. Las medianas y grandes explotaciones, que se dedican al cultivo de cana o a la ganadería lechera, se concentran en el sur-esle y sur-oeste de la zona; sobresale el bloque bien homogéneo de 650 micro-explolaciones de 1 ha (lo que no es autorizado por la ley que define un limite inferior de 2 ha para el distrito), en el sitio de la anciana laguna, con sus suelos muy impermeables.

2.4. La población residente en nuestra zona de estudio (2400 
habitantes) es relativamente débil en relación con las personas implicadas en el proceso productivo ( 7000 por lo menos) que en su mayoria viven en los pueblos cercanos (Armenia, Ciudad Arce,...). En el distrito los residentes se concentran en 4 caserlos, pero numerosos desplazados de guerra se han radicado recienlemente en las orillas de las calles o canales y constituyen una reserva de mano de obra abundante y rapidamente disponible, to que requieren los cultivos de horlalizas, por ejemplo.

2.5. La organlzación del riego y del drenaje no es homogénea; en la zona de las micro-unidades (antigua laguna) los agricullores que mantienen ellos mismos la red de canales, eligen "jueces de agua" que administran la distribución del agua. En las demás partes del distrito, canaleros y técnicos del Ministerio de Agricultura gestionan el agua y mantienen las infraestructuras, los usuarios teniendo que pagar cuolas por hectárea regada. Frente a la inseguridad del abastecimiento en agua por esta organización "centralizada," 2 varios agricultores con bastante recursos han construido pozos, comprado bombas individuales.

2.6. Para terminar, se esludiaron otros determinantes economicos que son el acceso al crédito, los circuitos de comercialización, las Intraestructuras y servicios. Cabe sefialar la debilidad y el fracaso de las intervenciones estatales en estos campos (por ejem., solamente $25 \%$ de los campesinos contratan préstamos con instituciones). Agentes privados (agroempresas y "coyoles") aprovechan de este vacio, no ocupado por asociaciones de productores, para controlar la comercialización de hortalizas y, al mismo tiempo, proporcionan adelantos a las cosechas.

\section{Los palsajes agrarios}

El mapa representa zonas por las cuales la articulación de factores estudlados anterlormente genera una problemátlca orlginal en relación con la producción agricola. No se trata de una construcción mecánica: recorridos sobre la zona nos mosiraron que estas dlstintas zonas corresponden realmente con paisajes agrarios diferentes.

\subsection{El minlfundlo dela antlgua laguna}

Esta zona relativamente importante (entre el 20 y el $25 \%$ del área tolal) es un conjunto aparentemente homogéneo de pequefas parcelas de una hectárea, rodeadas de árboles. Dado el muy malo drenaje de la tierra en la estación lluviosa, los minifundistas adoptan rotaciones culturales del tipo anoz-hortalizas o barbechos-hortalizas; en relación con el resto del valle, las sucesiones de los cullivos de verano lan poco no son muy variables al interior de esta zona: frijoles y pepino o tomates.

El "pantano" es la parte menos accesible del distrito; el mal estado de los caminos, la insalubridad que ahí reinan en la época lluviosa, la lalta de 
Y.PA $\aleph^{\circ}$ 1: LOS DISTINTOS PAISAJES AGRARIOS ( 0 ZONAS CON PROBLRATICA HOADGEVE) DE LA ZONA DE ESTUDIO.

( Elaboración sintética a partir de los mapas precedentes, y trayectos)

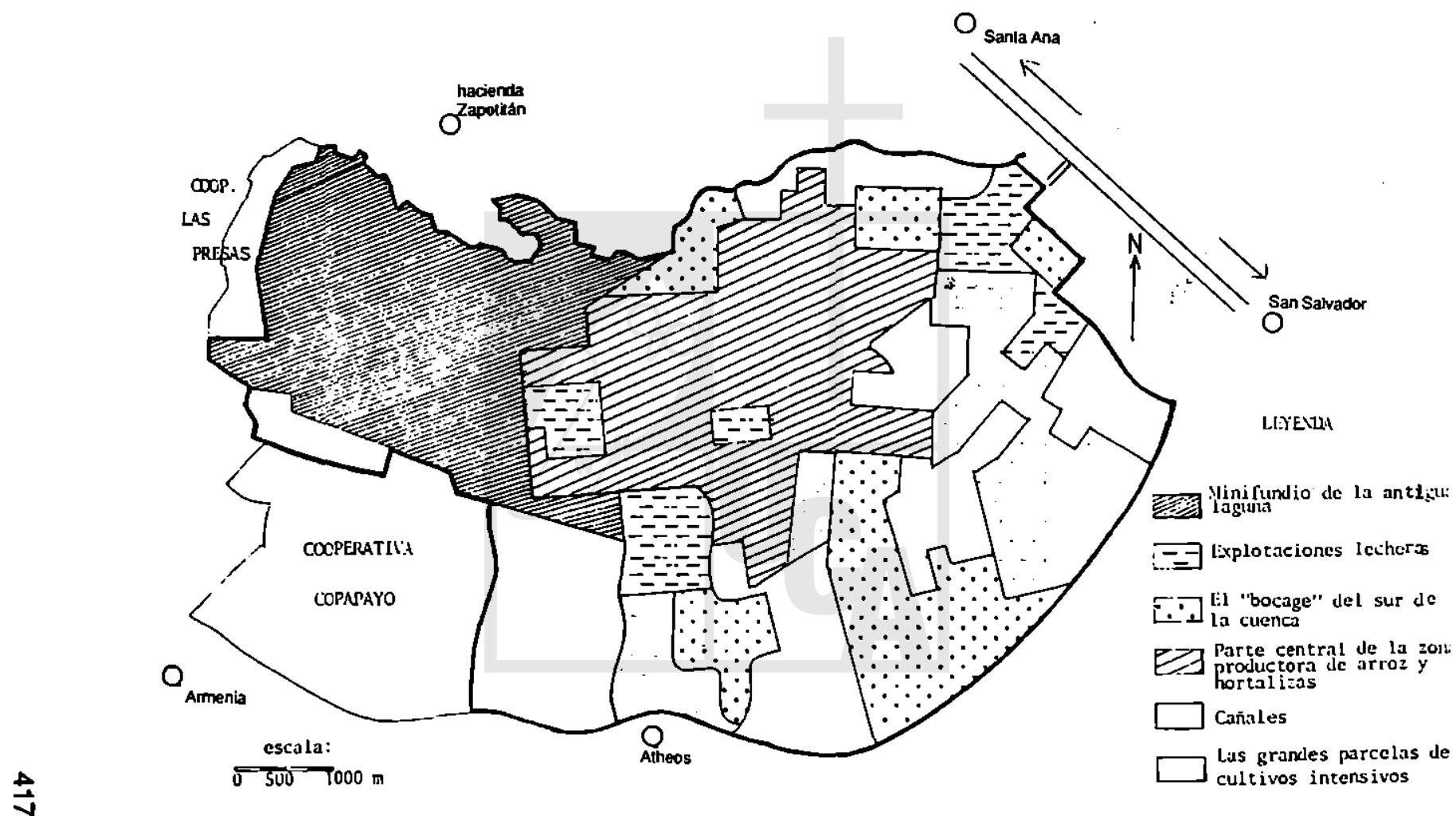


infraestrucluras sociales pueden explicar la ausencia casi total de residenles.

Asi, la problemática caraclerística de esla zona probablemente resultará del excedente de agua en invierno, del tamaño reducido de las explotaciones, de su aislamiento y de los "cuellos de botella" de los itinerarios ténicos de las producciones ahi encontradas: variabilidad de los precios, plagas, comercialización y crédilo.

Aunque parece destavorecido, el "pantana" goza de un triunto agronómico determinante, la total disponibilidad de agua para el riego en verano, característica que se debe de apuntar en paralelo, con la organización original de los campesinos de esta zona para la gestión del agua (exclusivamente supericial).

\subsection{Las explotaclones lecheras}

Con una área de 20 a 50 hectáreas, estas fincas dan forma a manchas amplias que son grandes pastos regados, agrupados alrededor del cazco, constituido por importantes corrales, estabulaciones y a veces salas de ordefio. En la finca no vive el propietario, sino el cuidador y unos colonos.

Estas explotaciones lecheras son bastantes diseminadas, pero generalmente se encuentran en la parte más baja del valle, en lugares pamlanosos en invierno, pero que no carecen de agua en verano.

\subsection{El "bocage" del sur de la cuencla}

Esla zona ofrece un paisaje de parcelas de 2 a 5 hecláreas, cercadas con árboles, la mayoria ocupadas en verano por cultivos diversificados; casi loda la zona eslá cultivada en maiz en la eslación lluviosa.

Los suelos son generalmenle bien drenados en invierno, pero carecen baslanle de agua en verano, por el no funcionamiento de los pozos (fuerte dependencia del agua subterránea), o por el alejamiento de los caudales. En estas partes del distrito bien proveidas en caminos de todo tiempo, existen muchas loliticaciones muy pobladas.

El acceso de agua para el riego en verano (adminislrado por el MAG), la disponibilidad de tierras a veces, son los principales laclores limitantes que se af́aden a los ligados a la producción, comercialización de maiz y hortalizas.

\subsection{La parte central de la zona, productora de arroz y hor- tallzas}

En esta zona, al contrario de la precedente, es el exceso de agua en invierno que constrine más la elección de los cullivos y su manejo. 
imponiendo el arroz, mientras que varias parcelas (más humedas) quedan incultas. La escasez de agua en verano es menos crucial que en la zona del "bocage" al no depender tanto de las aguas subterráneas. Se yuxtaponen microexplotaciones de 1 a 3 hecláreas y explotaciones más grandes de 5 a 20 hecláreas; muchas de eslas últimas son propiedades de urbanos que confian el manejo lécnico a un "encargado", o son tierras alquiladas por agrónomos, capitalistas, que emplean muchos jornaleros en la producción de horlalizas de verano.

Las orillas de las calles y de los canales parecen jugar un papel no desdenable; ahi se han radicado muchos desplazados de guerra. Además pequefios campesinos que no poseen potreros dejan su rebano pastar en los senderos.

\subsection{Los cafiales}

Ubicados en zonas generalmente bien drenadas, haciendas, canales de 20 a 50 hectáreas y más, definen un paisaje y una problemática especilica a este monocultivo. Fijamos la necesidad de explicar la existencia de eslas unidades relativamente extensivas en una zona de riego donde se encuentran alrededor unidades mucho más productivas.

\subsection{Las grandes parcelas de cultivos Intensivos}

En el este del valle, y en los suelos buenos (con una buena retención de agua pero sin mayor problema de drenaje, y de buena fertilidad), se encuentran grandes parcelas a menudo cultivadas solo en hortalizas, y regadas con sistemas particulares de riego (bombas individuales). La ausencia de árboles da una apariencia de "campo-abierto" a esta zona. Para estas "medianas" explolaciones (5 a 20 ha.), de las más tecniticadas 'del valle, los factores limitantes mayores son de tipo técnico o económico, fuerlemente ligados al proceso de producción y comercialización de las papas (muy cultivadas ahi), hortalizas y del maiz.

\section{HIstorla agrarla del Valle de Zapotttán}

La variabilidad geográfica del sistema agrario, revelada en la primera parte, va a enconirar su explicación en la historia agraria o sea en la evolución de las relaciones entre el medio "nalural" (delerminantes fisicos) y su ulilización por los grupos humanos sucesivos.

El actual Distrito de Riego de Zapotitán siempre ha sido una zona pantanosa, como lo testifica, por ejemplo, la presencia de numerosos aluviones lacustres. Por eso, ha represenlado, durante mucho liempo, un espacio secundario o "complementario" para las economias que lo rodean, hasta que su avenamiento recienle permitiera su puesta permanente en cultivo, lo que convirtió esta zona en un espacio estratégico 
para el pals.

En el presente articulo, nos limilaremos a un resumen de la historia agraria, subrayando algunos aspectos de la historia del proyecto (a partir de 1971).

\section{El sistema agrario antes del proyecto}

La hacienda de Zapolitán ( 6800 hectáreas de pastos, matorrales y pamano) tue adquirida por el gobiemo de Martinez en 1934, para adjudicarla a familias sin tierra (35000 hecláreas fueron asi "distribuidas" en todo el pals en una tentaliva de apagar los conflictos sociales, después de los eventos de 1932). La parte sur que constilufa lo esencial de nuestra zona de estudio (además, 3 pequefas haciendas (Capapayo, San Fernando y Belén) estaban en parte incluidas en el actual distrilo) se repartió en 700 lotes de 4 a 6 hectáreas cada uno.

A pesar de las primeras obras de drenaje realizadas por el Inslituto de colonización Rural (especialmente en 1954-56) y la intensa actividad de estos primeros produclores, la zona quedó insalubre, la milad siendo inundada en invierno, la tercera parte inutilizada en verano.

En el ano de 1961, aparece que unos 450 beneficiarios iniciales hablan vendido o hipotecado sus tierras, realizándose una concentración rápida de la tierra al benelicio de familias en su mayoría urbanas: a esta fecha, $10 \%$ de los propietarios poseían más de 20 hectáreas, 10 que correspondia al $61 \%$ del área.

Encomtramos entonces amtes del proyecto dos grandes tipos de unidades de producción:

- Unas 12 pequenas haclendas reconstituyen, en una escala menor, el sistema de ganaderla de engorde de la antigua hacienda de Zapolitán, aprovechando de la disponibilidad en agua para el forraje durante todo el ano.

- Numerosos pequenos productores, beneficiarios de la redistribución del ICR, colonos o arrendatarios, cullivan granos básicos y un poco de hortallzas (300 hectáreas en 1969). Alrededor de la laguna, se produce arroz en verano; en las zonas más altas (al sur) se logra implementar el malz y trijoles en invierno; mientras que en la franja inlermedla se cultiva arroz o maiz en invierno, hortalizas en verano ( 2 cultivos al ano).

La ublcación geográfica, las posesiones a fuera del valle, la superticie cultivada,... son factores que generan una diferenciación naciente dentro del grupo de estos pequefios productores cuyos sistemas de producción utilizan todavia pocos insumos al aprovechar de las reservas de 
fertilidad de los suelos (en 1961, más de la milad no usa abono químico (6)).

Por fin, es muy importante apumlar que existia un sistema de riego que, a partir de unas 15 presas y canales de tierra, lograba regar por gravedad unas 1600 hectáreas (6) en verano. Las pequenas haciendas que ocupaban las proximidades de los ríos (lugares estratégicos para el control del drenaje y del riego) desvíaban casí todo el agua en sus polreros, sin tomar en consideración los intereses de los campesinos más abajo. Estos se habian organizado bajo la administración de un juez de agua, electo, y remunerado por la alcaldia de Ciudad Arce.

\section{1970, el proyecto de rlego y avenamlento, $y$ sus con- secuenclas sobre los sistemas de producción}

\subsection{Contexto, objetlvo y reallzación del proyecto}

- A partir de los ańos '50-60, en las distinlas inslituciones inlernacionales y en la mayor parte de los gobiernos del tercer-mundo, se generaliza la convicción de que se podía vencer al hambre y "saltar las etapas que alejaban los países del norte y los del sur", gracias en el campo agricola, a la extensión de variedades de cereales de alto potencial genélico y a la transferencia de paquetes tecnológicos a través del financiamiento de grandes proyectos.

En América Latina esta visión tecnicista y tecnócratica del desarrollo fue especialmente promovida por la "Alianza para el Progreso", integrando además, reformas económicas y sociales (reforma agraria sobre todo) juzgadas estratégicamente necesarias por los Estados Unidos, apoyadas por el capilalismo industrial, las clases medias recientes y, por supuesto, las mayorias rurales.

En El Salvador, las políticas agrarias pusieron énfasis en los aspectos técnicos (dilusión de variedades hibridas de maiz, promoción de insumos,...) para tratar de evadir cualquier reforma agraria ${ }^{4}$, esperando mantener la reproducción económica de los minifundistas (y el orden social), como para responder a la demanda urbana creciente, via un aumento de los rendimientos de granos básicos. Pero, los resultados positivos iniciales (rendimientos multiplicados por 2 entre 1960 y 1973 para el maíz) se agotaron al inicio de los anos '70, tropezando esta vez directamente contra limilaciones estructurales: acceso a la tierra, cualidad de la tierra, crédito, circuitos de comercialización, etc.

- El Proyecto de Zapolitán, cuyas orientaciones se explican en parte por este contexto nacional, lue precedido de 10 anos de consultoria ${ }^{5}$. Los objelivos generales asignados fueron de aumentar las producciones de hortalizas y leche, con un incremento de $150 \%$ de las tierras regadas y 
de su productividad, para sustituir las importaciones de estos productos.

Pero para cumplir con estos objetivos, de "interés nacional", no hubo un consenso sobre los medios, más que todo al nivel de una posible redistribución de tierra: bajo la presión de los grandes propietarios de Zapotitán, lue rechazada la propuesta de los consultores (división de la zona en propiedades de 3-6 hectáreas) limitandose a fijar el área mínimo a 2 ha. y el máximo a 50 ha. Entonces, el proyecto, de acuerdo a las relaciones de fuerzas locales (y nacional) y a la ideología del desarrollo dominanle, se restringió a optar solamente por cambios técnicos y administrativos que debian drenar la cuenca y reemplazar el antiguo sistema de riego por otro más "eficiente".

- Apoyandose sobre un presupuesto de USAID inicial de 11 millones de colones ${ }^{6}$ se implementó la nueva infraesiructura (canalización de los ríos, construcción de una red de caminos, de canales de drenaje, como de riego, perforación de 20 pozos equipados de bombas electricas,...).

La laguna, con eslas obras, fue tolalmente desaguada, permitiendo la redistribución de esta tierra del eslado a 650 campesinos, en mayorla arrendatarios en las zonas circundantes. En este caso los campesinos (organizados en brigadas de trabajo) realizaron una gran parte del trabajo de avenamiento y les fue dejado la organización del riego, relomando las características del antiguo sistema (elección de juez de agua), mantenimiento a cargo de los usuarios,...).

Para el resto del valle, una oficina de técnicos fue encargada por el MAG de administrar la distribución del agua, con la ayuda ejeculiva de cuatro canaleros.

2.2. Intensificación de los sistemas de producclón de granos básicos y hortalizas

El proyecto creó nuevas condiciones agro-ecológicas que incitaron rapidamente a los pequefios y medianos productores a adoplar las sucesiones de 263 cultivos en el año. El maíz pasó de 1600 a 2300 ha entre 1970 y 1974 y las hortalizas de 300 a 500 ha (16); estos cultivos se extendieron a una gran parte de la zona, más que todo como consecuencia del avenamiento. La relativa estrechez de sus lierras, la escasez de tinanciamiento externo, las experiencias técnicas ya poseidas, hicieron que estos sistemas de producción luesen la única y lógica alternativa para incrementar el margen bruto de los pequenos productores (la cana no maximiza el ingreso por manzana, la ganaderia requiere muchas inversiones,...). Electivamente se inició una real dinámica de acumulación: El riego y el drenaje, que habian provocado por si mismo un aumento sensible de los rendimientos (en invierno más que todo), permitieron a los agricultores sacar disponibilidades financieras adicio- 
nales $e$ invertir en la cantidad de insumos que maximizaba el nuevo margen bruto polencial (lo que levantó aún más los rendimientos: de 1,8 toneladas métricas por hectárea a 3 Vha entre 1970 y 1975 para el maiz $(10,18))$. Además, la generalización de estas rotaciones de cultivos implicaba el empleo de la mano de obra durante todo el ano y una mejor repartición de los ingresos monelarios.

Pero esta intensificación (en capital y trabajo) signiticaba una integración creciente a los mercados de insumos, de servicios y de produclos agrícolas, o sea una dependencia más fuerte con los "coyoles", visto que no hubo ninguna política del estado para responder a eslas nuevas necesidades, tampoco organizaciones de productores eficientes.

Además, otros tres fenómenos redujeron, después de un "salto" en los primeros anos, el margen brulo de los pequehos productores (caida de los margenes reales de $50 \%$ para el chile y el tabaco, de $60 \%$ para el tomate, de $10-20 \%$ para los granos básicos, entre 1973 y 1986):

- El surgimiento de un nuevo tipo de riesgo hidrologico, debido a la defectuosidad de la infraestructura de riego. (detención progresiva de los pozos).

- El desarrollo de las plagas por consecuencia de la sucesión rápida de cultivos con las mismas características fitopatologicas, lo que obliga a los productores a realizar lumigaciones preventivas más y más numerosas.

- Por tin, el aumento más rápido de los precios de los Insumos, desde la milad de los anos ' 70 , que los precios de compra al productor de las hortalizas y granos básicos.

\subsection{La evoluclón de las grandes unldades de producción}

El proyecto provocó una transformación radical en los sistemas de producción de las lincas más grandes; ellas fueron realmente, o formalmente, divididas en propiedades inferiores de 50 hectáreas y abandonaron tolalmente la ganaderla de engorde para dedicarse a 2 especulaciones posibilitadas por las nuevas condiciones agro-ecológicas de la zona y impulsadas por un entorno económico favorable:

El avenamiento del distrito permitió la extensión de la caḱa (el área paso de 240 ha en 1969 a 1100 ha en 1973 (16)), en una época de precios internacionales allos y de luerte desarrollo de la agro-industria azucarera salvadorena. Para estos propielarios ausenlislas, este cambio productivo generaba una tasa de ganancia más alla, traía una seguridad importante (regularidad de los rendimientos, cuidado limitado),...), y la venla de los animales reproductores liberaba un capital disponible para otras inversiones. 
Con una lasa de ganancia más o menos igual a la de la caña, la producción de leche necesilaba una inversión en capital mucho más alta, que permitía extraer un margen bruto por hectárea mucho mayor. Varios grandes productores, para quienes los ingresos de su finca de Zapolitán constilulan generalmente una buena parte de sus ingresos tolales, y que lograron. integrarse a las centrales lecheras en expansión (debido al crecimiento de la demanda urbana), escogieron realizar una inversión a largo plazo en la ganadería intensiva de leche (razas mejoradas importadas, forraje de corte, etc.).

\subsection{Aparlción de nuevos productores y diferenclación de los pequeños agricultores}

La implantación del proyecto convirtió el valle de Zapotitán en una zona de alta renta diferencial, muy atractiva para inversionistas, productores, trabajadores, elc.

- Con la redistribución de la antigua laguna se constituyó un grupo muy homogéneo de campesinos minifundistas ( 1 heclárea cada uno) con su propia organización para el riego.

- Numerosas personas que ya tenían un dominio técnico de los cultivos de hortalizas (agrónomos,...), buscaron alquilar unas parcelas en Zapotitán para aprovechar de las allas ganancias polenciales.

- En esta misma óptica, familias urbanas poseyendo un cierto capilal (funcionarios, profesionales, militares,...) compraron propiedades de 3 a 10 hectáreas, empleando un "encargado" responsable del manejo técnico de las producciones (hortalizas, trutales o pequefa ganaderia). Esto representa hoy dla la mayoria de las compras de tierra en el distrito (además se especula sobre el valor monelario de la tierra que fue multiplicado por 10 en 15 afios).

- Empresas agroindustriales, y más que todo granjas avícolas, se radicaron en Zapotitán, zona de acceso fácil, cerca de San Salvador, y no conflictiva.

- Por último, 2 elementos más recientes influyeron en la estructura económica y social de nuestro sistema agrario: la guerra provocó, a partir de 1980, una migración constante de "desplazados de guerra" hacia los terrenos públicos (caminos, canales,...) de Zapotitán constituyendo una reserva de mano de obra. La tercera lase de la reforma agraria permitió a cierto número de campesinos sin tierra adquirir una parcela que alquilaban (promesas de venta sin pagar las anualidades) pero redujo considerablemente la oferla de lierra alquilable en la zona.

- En esie contexio de trastomo social y de apertura creciente a los mercados, el conjunto de los pequenos productores se diferenció rapi- 
damente: hubo una real acumulación para muchos de ellos, pero son generalmente los aportes financieros externos (dolares mandados por familiares), la existencia de otro pedazo de tierra fuera de Zapotilán, el tamaño de la familia, que lo explican. Algunos lograron ampliar su propiedad, pero por 10 menos $5 \%$ de ellos (menos de 10 ha) vendieron sus parcelas entre 1975 y $1981(8,18)$. Varios trataron de diversificar su producción (flores, plantas aromáticas, nuevas hortalizas,...), buscando una renta de mercadeo, mientras que olros se integraron vía un contrato, a una agro-empresa (tabacalera,...).

\subsection{Breve evaluación del cumplimlento de los objetlvos Inlclales del proyecto}

En el inicio de los años 70 , el área regada tolal aumenla de 30\% (pasa de 1600 ha a 2100 ha), así como los rendimientos, pero en proporciones sin embargo inferiores a lo que era previsto. Los rendimienlos crecieron más que todo para el maíz, es decir un cultivo de invierno que, antes del proyecto, sulria bastante la escasez de drenaje.

A partir del afio 1976, la delención progresiva del funcionamiento de los pozos (12 pozos utilizados en 1976, 6 en 1987) provocó una caida sensible de disponibilidades en agua del distrito (de $30 \%$ entre 1973 y $1979(B))$.

A partir del '76, las áreas regadas bajaron, hasla alcanzar hoy dia un nivel más o menos igual a la superficie que era regada antes del proyecto (unas $1600 \mathrm{ha}$ ); los rendimienlos, cualquiera que sea el cultivo se estancan. Además, hubieron efectos "contrarios" a los esperados que son:

- El desarrollo de la caña de azúcar y la baja de las áreas en pastos en las grandes explotaciones.

- El eslancamiento, incluso la baja del margen bruto por hectárea de los campesinos, por la proliteración de plagas cuya eliminación requiere más y más insumos y trabajo.

- La captación de una parte creciente de la producción por los intermediarios proveedores de crédito.

- El coslo de la administración, del mantenimiento de las iníraestructuras y la cornupción de los canaleros.

En el balance del proyecto, hay que distingulr el caso partlcular de la "zona 1" (antigua laguna). Esta zona, cuya administración hidrologica esla "en las manos" de los usuarios, no parece tener mayor problema de riego, y aprovecho ciertamente del drenaje, que permilio cullivar tierras antes panlanosas. Las orientaciones agronómicas de las "microfincas" de esta zona corresponden exactamente a los objetivos del proyecto. No obstante, quedan problemas serios de aislamiento, de co- 
mercialización y crédiło.

\section{Tipologia de los productores agricolas de la zona de es- tudlo}

Si bien la historia agraria nos ha ensefrado globalmente el origen de los distintos paisajes y la evolución dilerenciada de las unidades de producción, conviene llevar a cabo un análisis más preciso de la diversidad de los productores para entender sus comportamientos Irente al ambienle socio-económico salvadorefio actual. Por eso vamos a construir una tipologia que presente las racionalidades lipicas encontradas y los sistemas de producción correspondientes, y que se justifica por el deseo de privilegiar la búsqueda de los mecanismos explicativos del funcionamiento del sislema agrario.

Siguiendo la metodologla expuesta en la primera parte del Irabajo, hemos empezado a construir un "cuadro de análisis" estructural, tomando en cuenta los criterios de diferenciación que pareclan haber influido históricamente los sistemas de producción; ellos fueron básicamente:

- La tierra disponible y su tenencia.

- El modelo de relación con el mercado.

- El modo de acceso al agua.

- La disponibilidad en capital, especialmente externa.

- La composición de la fuerza de trabajo.

A eslos criterios que parecian determinar objelivamente (pero no totalmente) las racionalidades de los sistemas de producción de Zapotitán, hemos af́adido el estudio de olros que van a representar directamente (pero no explicar) estas lógicas distintas; estos fueron:

- Las producciones principales y su manejo técnico.

- La intensificación en capital.

- El ingreso monetario por heclárea.

- La tasa de ganancia.

La confrontación de estos dos grupos de indicadores con la realidad agraria y su historia, revela (siguiendo el acercamiento iterativo) los distinlos conjuntos de delerminantes, llegando a la caracterización de los diferentes tipos existentes y a las racionalidades correspondientes.

Dentro de la complejidad aparente, hemos identiicado 4 principales racionalidades que pueden recubrir los distintos "subtipos".

A. El primer tipo de lógica corresponde a un comporlamiento rentista y reune esencialmente los productores de cana. (Tipo I).

B. Dentro de la segunda lógica, de maximización de la tasa de retorno del capital invertido, distinguimos 3 tipos: 
- Las grandes fincas lecheras (II-1)

- Los "farmers" (II-2)

- Las pequenas explotaciones de urbanos (II-3)

C. La tercera racionalidad económica que se encuentra consiste en maximizar el ingreso monetario familiar por hectárea; los subtipos identiticados son:

- El pequeno productor de granos básicos y hortalizas. (III-1).

- El agricultor-ganadero (III-2).

- El campesino en contrato con una empresa (III-3).

D. Por fin se encuentra lambién una logica inmediatista (o de "sobrevivencia") representada por los campesinos sin tierra (IV-1) y los colonos (IV-2).

La redacción completa de la lipologia da para cada lipo una sintesis de los casos estudiados, tralando de definir concretamente su origen histórico, su sistema de producción, los factores limitantes que encuentra y calculando algunas variables económicas que permitiran compararlos. En esle articulo, subrayamos solamente los elementos fundamentales que explican las opciones de los distintos tipos, as/ como sus principales factores limitanles.

\section{Los rentIstas ausentlstas productores de cafla. (Tipo I).}

\subsection{Racionalldad soclo-económica}

Esta primera racionalidad económica esla determinada por las condiciones siguientes:

- Exisle una alla disponibilidad en tierra, por lo menos 10 ha, pero sobre todo alrededor, o más, de 50 ha. Estas unidades de producción estan generalmente divididas juridicamente entre famillares, mientras que exista una sola adminislración: se puede entonces considerar estas explotaciones como una única unidad de producción.

- Los propietarios, ausentistas, y que muy a menudo han heredado de la explotación, se dedican a otras actividades (profesión liberal, comercial, industrial), y pueden tener otras fincas a fuera del distrito.

- Esta tierra esta ubicada en general en las zonas bien drenadas y que no tienen toda la seguridad de ser bien regadas en verano.

Sobre la base de estas condiciones objetivas, a las cuales se anaden una historia y una práclica especificas de la clase terrateniente salvadorena, se disena un comportamiento rentista de los productores que determina el funcionamiento de las unidades de produoción: esta logica consiste en aprovechar la tierra poseida para extraer un ingreso total 
relativamente importante, sin invertir en la finca (o lo menos posible), minimizando los riesgos. Esto puede conducir, al extremo, a la venta de la tierra para disponer, a corto plazo, de un ingreso financiero.

Si bien los precios de la caña han bajado en los últimos años, afectando su tasa de ganancia, el cullivo - que además liene una cierta inercia frente a las variaciones del mercado por ser perenne- sigue respondiendo a una racionalidad de rentista. La renta esla preservada por una alta protección otorgada a la producción de cafla, manteniendo los precios del azúcar nacional al doble de los precios intemacionales.

\subsection{El sistema de producción}

El sistema de producción se caracleriza por:

- Un capital inmovilizado muy reducido (pocas operaciones estan mecanizadas y la canta es renovada solamente cada 6067 afios).

- El uso sumamente desequilibrado en el tiempo de una fuerza de trabajo asalariada (la zatra, en pocos dlas, emplea más de $80 \%$ de la mano de obra que necesita en todo el ano). azúcar.

- La integración de eslas unidades de producción con ingenios de

\subsection{Tasa de ganancla y valor agregado obtenidos}

La ganancia bruta anda por los 1000 colones por manzana, lo que da una tasa de ganancia bruta de $3-5 \%,{ }^{7}$ pero, de $28-30 \%$ al no incluir el valor monetario de la tierra; eso tija el ingreso anual de una finca de 80 manzanas a más o menos 80.000 colones.

El precio de alquiler de la tierra es de 1000 a 1500 colones por manzana al ano; pues el dueho tendrla interes en alquilar la tierra a productores, lo que no hace, supuestamente por medio del decreto 207 que lo podrla obligar a vender a un precio más bajo que lo que se puede esperar en el fuluro.

El valor agregado se acerca a los $2000-2200$ colones por manzanas, to cual se reparte entre 1000-1200 colones de sueldos y 1000-1200 colones de plusvalla captada por el dueno.

\subsection{Factores IImitantes y perspectlvas}

Más que todo, la problemática del azúcar esta ligada actualmente a la debllidad del precio internacional: la reducción de la demanda, que se traduce para El Salvador, por la disminución de su cuola de exportaclones hacla los EE. UU., ofrece pocas perspectivas para el cullivo de la cana, a pesar de las predicciones, que se hicieron después de la crisis 
pelrolera sobre las posibilidades de producir carburantes a partir de alcohol: el precio internacional actual (1987), alrededor de 7 centavos de $\$$ por libra, determina un valor de producción por heclárea inferior a los costos intermediarios del pais de mejor productividad del trabajo en esle rubro, Brasil.

Además, en un proyecto de riego que toca a las mejores tierras del país, este sistema de producción genera poco empleo y poco valor agregado, mientras que exislen otras alternativas más "productivas", lo que nos indica que estas propiedades de familias ausenlistas, no cumplen con los objetivos del proyecto.

\section{Las "empresas agricolas" capltallstas}

En estas unidades de producción, se trata de invertir un capital imporlanle, propio o prestado, en la intensificación agricola para maximizar la tasa de ganancia correspondiente. Para esle "empresario" o esta empresa, la elección de las producciones se hace basicamente en función de los factores siguientes:

- Las relaciones de precios existentes en el momento, y las tendencias esperadas, que definen los niveles de ganancia.

- Los riesgos técnicos o económicos atribuidos a cada produción.

Estos factores van a explicar la variabilidad encontrada en esle grupo, lo cual se articula alrededor de 3 lipos principales: las fincas lecheras, los pequenos productores capitalistas "farmers", los pequenos productores urbanos.

Al contrario de los rentistas de la cana, estos empresarios o sociedades anónimas toman algunos riesgos, inmovilizando a veces mucho capital por heclárea; por eso tienen que conlrolar más directamente el proceso de producción (sin por lo tanto residir en Zapotitán) y tratar de asegurarse el acceso a los factores inseguros que son esencialmente, el agua y la comercialización.

\subsection{Las fincas lecheras. (Tipo II-1)}

Estas unidades de producción corresponden a grandes fincas, ubicadas más bien en zonas relativamenle húmedas en invierno, y que son facilmente identificables en el paisaje: existen como 5 fincas, teniendo más de 25 hectáreas y hatos superiores a 100 vacas lecheras, que conslituyen "islas" verdes con pastos bien regados. A ellas se anaden algunas unidades más pequehas (20-50 vacas).

La cuestión que surge ahora es la siguiente: ¿con un mismo tipo de acceso a la tierra que las fincas caf́aleras, por que estas unidades inmovilizan mucho capital, especialmenle en un hato importante, y to- 
man riesgo en producir leche? o sea, ¿qué elementos podrian explicar esta lógica distinta?

- Primero, aparece que estas fincas se ubican en zonas generalmente muy húmedas en invierno, lo que impide la producción de caña y permile, al contrario, un buen abastecimiento de forraje. Pero este delerminismo agronómico juega, una vez los determinantes socio históricos son cumplidos.

- Una serie de condiciones muy lavorables, en los af́os '70 (crecimiento de la demanda interna de leche, desarrollo de centrales lecheras, implementación del proyecto de riego y de las infraestructuras de comunicación, ...) incitaron algunos grandes produclores a dejar la crianza de engorde para invertir a largo plazo en la producción lechera.

- Además, el origen y la implicación del propietario son bien distintos. Este es un único dueño, liene un conocimiento lécnico importante (dos son ingenieros agrónomos) y se implica directamente en la administración de la finca, aunque no residen en Zapolitán. (Uno de eslos productores de leche es una sociedad anónima (Moore Comercial)).

\subsubsection{Sistema de producción}

- La primera característica de este sistema de producción reside en inmovilización muy fuerte de capital por hectárea.

- La tierra se encuentra en cantidad importante para el distrito, generalmente cerca del "límite" de 50 ha.

- El hato numeroso esta constituido por razas de alta polencialidad lechera: Holstein (importadas de los EE. UU.) o Braun Swiss.

- La infraestructura y el equipo técnico representan lambién una inversión relativamente alta: Iractor, máquinas de ordefhar - a veces-. picadoras, equipo de refrigeración para la leche, elc,...

En uno de los casos estudiados, el valor de suslitución de las inmovilizaciones y de la tierra alcanzaba los $₫ 70.000$ por manzana.

Esle sistema de producción corresponde a una ganadería lechera intensiva, con un cargamento que puede alcanzar 7 unidades animales por hectárea, lo que implica la producción de lorraje de corte regados y de allo rendimiento, y la compra de una gran parte de los alimentos del hato. Por eso, la unidad de producción es muy dependiente del abastecimiento externo, eventualmente proveniente de otras unidades del mismo duefo, pero en grandes proporciones importadas.

El sistema de producción queda relativamente intensivo en trabajo (alrededor de 150 días de trabajo por manzana); se logró un aumento de la productividad de la mano de obra empleada, con la compra de vacas de 
atho potencial, el uso del riego, de la inseminación arlificial,... Pero no se ha mecanizado las operaciones como el corte del forraje (que se hace con el machete), el transporte del estiercol, por la disponibilidad en mano de obra poca caliticada y barata. La fuerza de trabajo esla constituida por un asalariado permanente Importanle (un trabajador por 203 manzanas durante todo el ano).

Por tin, la relación del sistema de producción con las industrias lecheras es determinante; de un lado, la "Foremost", principal "cliente" en Zapolitán, garantiza un precio de compra estable y relativamente elevado para el mercado nacional ( 11.20 en 1987, mientras que el precio de compra por los demás clientes podía caer a 60.90 ) y se encarga del Iransporte de la leche hacia la fábrica. En contraparte, la Foremost beneficia de una leche de buena calidad sanitaria, y más que todo, reduce sus costos de recolección y de administración, con un número reducido de fincas de alla productividad. Pues, se puede decir que estas unldades de producclón beneficlan de una clerta renta de sttuación, estando integradas a la industria lechera, y entonces, al mercado privilegiado de la leche tresca consumida más que todo por las capas urbanas ricas.

Si es cierlo que, como lo manifiesta PROLECHE, los margenes de la producción lechera tienden a bajar por el encarecimiento de los Insumos y la competencia de la ayuda alimentaria que implde el aumento de los precios de la leche, la ganancia queda muy alta, entre 5.000 y 6.000 colones por manzana (una ganancia total de 240.000 colones para una finca de 60 manzanas estudiadas). La tasa de ganancia, sl incluimos el valor de todas las inmovilizaclones (tierra, vacas,...) es de 8-9\% (un poco inferior actualmente a la tasa de ganancia nacional). El valor agregado por manzana es el más alto del distrito, 8.000 a 10.000 colones por afro según la carga por ha, y para dos casos esludiados, se compartla entre $20 \%$ para la remuneración del Irabajo, 20 a $25 \%$ en cargas financleras y el resto en ganancia.

El valor agregado por dia de trabajo es entonces sumamente alto, 60 a 70 colones, mientras que su remuneración es de 10 colones para los trabajadores "no calificados", lo que refleja las fuertes inmovilizaciones existentes en capital y tierra.

\subsubsection{Conclusiones}

- Si la rentabilidad financiera (de acuerdo con una lógica capilallsta) de las fincas lecheras se mantiene gracias a un hato de alta potencialidad (renta de capitalización), esta es cuestionada por las dificultades de adaptación de este hato a las condiciones agro-ecológicas de Zapolttán: las exigencias sanitarias y alimentarias de las Holsteins son muy preclsas. En una finca encuestada, una docena de estas vacas hablan muerto en 
1987 y varias otras padecian de descalcificación. En una otra finca, el productor empezaba a cnuzar esta raza con otras más rúslicas, al perjuicio del nivel de producción por vaca.

- El allo valor agregado generado por manzana responde totalmente a los objetivos del proyecto de riego, por el uso intensivo del agua para forrajes productivos de corte; pero conviene senalar la problemática de la repartición de este valor agregado que conforta el modelo de acumulación polarizado que ha llevado a la crisis salvadorena actual.

\subsection{El pequeno productor capltallsta "farmer". (Tipo II-2)}

Este sistema de producción es caracterizado por un actor bien definido que Invierte a corto plazo el capilal que dispone, en la producción que maximlza su ganancia: cerca, por el tipo de relaciones de producción que establece, del capilalista ingles "farmer" del Siglo XIX, este productor, en general, alquila la mayor parte de la tierra que cultiva (entre 2 y 40 hectáreas) y emplea una mano de obra numerosa, con el objetivo de aprovechar de la alla renta diterencial de las tierras del distrito y de la sobreganancla correspondiente. A la dilerencia de las fincas lecheras o de las granjas avicolas, la inmovilización en capital fijo es reducida; solamente lo constituyen un vehículo, indispensable para comercializar su producclón, una bomba de riego que traslada en cada una de sus parcelas, y herramientas de base (bomba de fumigación, azadones,...).

Los cultivos de hortallzas bajo riego (4 65 meses), de arroz y, en clertas zonas, de malz (5 meses), responden a esta lógica de maximlzación de la tasa de ganancia a corto plazo. Si se logra implementar 3 cultivos en el afio (incluyendo 1.500-1.800 colones de alquiler) puede llegar a una ganancia de casi 5.000 colones, o sea una lasa de ganancia del capltal global que alcanza los $50 \%$, por mucho superior a lo que se puede esperar en otras actividades industriales o comerciales.

\subsubsection{El acceso a los medios de producción y a la tlerra}

Las posibilidades limiladas de alquilar la tierra en condiciones favorables, de acuerdo con la lógica de este productor capilalista, constituyen la principal restricción a su expansión (área polencialmente alquilable reducido, búsqueda de las parcelas con acceso seguro al agua de rie90,...).

La dlsponibilldad en capital financiero limita también fuertemente el número de estos productores: su racionalidad de maximización de la tasa de ganancla se encuentra a partir de un mínimo de ingreso total asegurado (más o menos 1.000 colones mensuales), o sea a partir de un área minima de 2-3 hectáreas, lo que implica una disponibilidad financiera minima (por lo menos 25.000 colones por ano), para los gastos de 
campana. Si se trata de aprovechar al máximo de los préstamos bancarios para las hortalizas (13\% de interés anuales), el "farmer" necesita recurrir generalmente de manera másiva al autotirianciamiento. Por eso, la actividad comercial que puede tener paralelamente proporciona a menudo el adelanto para los cultivos de hortalizas.

El conocimiento técnico del productor representa otro elemento limitativo: vistos los riesgos importantes relacionados con la producción en grande escala de hortalizas (plagas, enfermedades, comercialización, conservación), el dominio técnico de estos cultivos es una exigencia; por eso, enconlramos, deniro de este grupo de productores, muchos agrónomos (o técnicos agricolas) y antiguos cuidadores.

\subsubsection{El slstema técnlco de producclón}

El sistema de producción del "Yarmer" se caracteriza generalmente por la succesión de los cultivos de arroz o maíz en invierno, y de hortalizas o papas en verano. Si la determinación del cullivo de invierno se hace más que todo en función de las características del terreno (empantanamiento), son principalmente los precios y la tasa de ganancia esperados, sus probabilidades de variación, y la experiencia del productor, que van a orientar la elección del cultivo de verano.

- En primer lugar, se puede notar la dificultad para un productor de Zapolilán de lograr implementar 3 cultivos en el año: el cullivo de máiz (grano) o arroz necesitando 5 meses, quedan 7 meses dificilmente aprovechables para 2 cultivos.

- La existencia de luertes picos de trabajo, más que lodo para las siembras y los trasplantes, implican el empleo de una mano de obra temporal numerosa; solamente una fuerte disponibilidad financiera puede permitir superar sin mayores problemas esta necesidad de emplear rapidamente mucha mano de obra, hasta una cierta área de cultivos.

- La necesidad de recurrir más y más al empleo masivo de insumos, el aumento más rápido de sus precios que el de los productos agrícolas afeclan cada ano los margenes de ganancia, especialmente de las hortalizas. Pero el "farmer", por su disponibilidad financiera alia, supera todavia esta crisis, oplando siempre por una solución "más tecnificada", utilizando nuevos productos fitosanitarios y logrando allos rendimientos.

- Al tener una bomba individual, puede suslraerse en parte de la dependencia con el distrito, si la parcela no esla lejos de un rio o de un capal principal.

- La comercialización de las hortalizas conslituye quizas el punto más estratégico; no obstante, el "farmer", al comercializar por si mismo su producción, obtiene margenes de ganancias de lo más altos. Algunos de 
ellos se aseguran directamente un mercado como los supermercados, la Fuerza Armada, etc.

\subsubsection{Cálculos de varlables económicas}

En el caso de un sistema de producción arroz-chile, podemos sacar las variables económicas siguientes:

- La ganancia, de 3.000 a 4.000 colones por manzana en 19861987, da una lasa de ganancia de unos $40 \%$, a veces $50 \%$. Para 10 manzanas, eso corresponde a un ingreso anual de 30 a 40.000 colones, completado eventualmente por los ingresos sacados del negocio de hortalizas.

- El valor agregado producido oscila entre los 7.000 y los 8.000 colones por manzana, de los cuales solamente la tercera parte va a la remuneración del trabajo. El resto se comparte más o menos entre un $45 \%$ para el productor (ganancia) y el $20 \%$ para el pago de la renta.

- El trabajo total que se aplica a una manzana en un año varia entre 220 y 300 dias por manzana (incluyendo el trabajo de administración realizado por el farmer).

\subsubsection{Conclusión}

Estas unidades de producción capitalistas podrian extenderse si se elaborara un cuadro jurídico preciso que defina y garantice las relaciones de arrendamiento: esta solución "politicamente aceptable" permitiria por lo menos reemplazar la caña por cullivos de alto valor agregado.

\subsection{Los pequenos productores urbanos. (Tipo II-3)}

Este último tipo corresponde a una pequefía finca, entre 3 y 15 manzanas, propiedad de un ciudadano que puede ser allo funcionario, militar, arquitecto, abogado, elc. Este miembro de la "nueva burguesia" salvadorefia ha logrado comprar, en los últimos afios, un terreno en Zapotitán, esta inversión reciente ${ }^{8}$ respondiendo al objetivo de rentabilizar un capital naciente, y lodavía relativamente reducido.

El propietario no tiene ni el liempo, ni generalmente el conocimienlo técnico para manejar directamente su finca. Por eso deja todo el manejo técnico a un cuidador que vive en la finca y que tiene un sueldo mensual fijo (entre 300 y 500 colones). El cuidador contrala la mano de obra externa y cuida los cultivos mientras que el dueño, que pasa generalmente cada lin de semana, controla la gestión financiera, comprando los insumos necesarios y cobrando directamenle el producto de la venta al negociante.

Si la compra de un terreno en Zapotitán es en si una inversión —por el 
aumento constante del precio de la tierra- el propietario va a implementar las producciones que maximizan la rentabilidad de las inversiones bajo las limitaciones impuestas por la relaliva escasez de su capital, y especialmente la reducción del área de su finca.

Los cultivos de granos básicos y hortalizas, las plantaciones de frutales y evenlualmente el engorde de un ganado van a responder a sus objelivos.

En el caso de una producción de hortalizas y granos básicos, los itinerarios técnicos van a ser muy similares a los que sigue el "Tarmer": empleo masivo de mano de obra externa, alto consumo en insumos, etc. Las diferencias se encuentran más que todo en:

- Una inmovilización más tuerte de capital tijo al nivel del riego (la tierra es en propiedad).

- Sobre todo, en una repartición distinta del producto brulo, debida a relaciones de producción dislintas: si bien no hay que pagar una renta, el mantenimiento de un cuidador aumenta notablemente los costos de mano de obra.

En este caso, el productor capitalista no toma en cuenta solamente la lasa de ganancia (sobre el capital "consumido"), sino más bien la rentabilidad global de su inversión, realizando un cálculo sencillo de actualización de las ganancias esperadas en función del capital "consumido" e inmovilizado (en el cual se incluye la compra de la tierra); esta alcanza un $10-12 \%$.

Una plantación frulal (papayos, cltricos, musaceas), que corresponde a una inmovilización más importante (con más anos de crecimiento antes de entrar en producción) proporciona generalmente una ganancia menor por manzana (entre 2.000 y 3.000 colones para los cítricos), pero con costos menores (hasta 2.000 colones en insumos y alrededor de 1.500 colones para el trabajo), lo que finalmenle da una tasa de ganancia equivalente (o un poco inferior).

Estas unidades de producción que se han multiplicado desde el inicio del proyeclo, son caracteristicas de distritos de riego ubicados cerca de ciudades y que no estan sometidos a controles estrictos de la acumulación de la tierra. la burguesla, atraida por una alta renta diferencial, realiza asl una inversión a largo plazo segura, caplando la mayor parte del valor agregado, relativamente elevado, que se produce en su finca.

\section{Los campesinos Intensivos de Zapotitán}

\subsection{Raclonalldad económica}

A esle tercer grupo general corresponde una Kógica bien distinta de la 
precedente; no se trata de maximizar la tasa de retomo del capilal del productor, sino de maximizar los ingresos monelarios familiares por hectárea. Los factores objetivos que determinan esta racionalidad son principalmente los siguientes:

- La tierra empieza a ser un recurso relativamente escaso (hasla 5-7 manzanas), especialmente en lunción de la fuerza de trabajo disponible.

- Esta fuerza de trabajo casi no liene un costo de oportunidad (hay pocas posibilidades de empleo externo), to que implica el uso de la mano de obra familiar en primer lugar, completada por el empleo de jornaleros para resolver los numerosos picos de trabajo.

- El capital acumulado, a veces muy reducido, tiene su origen en la pequena producción agricola, esencialmenle a Iraves de la redistribución de tierras en el distrito.

- Al contrario de los tipos precedentes, por su objelivo de maximizar sus ingresos por manzana, el campesino no puede tomar el riesgo de vender su tierra para invertir el dinero correspondiente en sectores no agricolas.

Los sistemas de producción, basados esencialmente sobre los cultivos de hortalizas y granos básicos, completados a veces por la crianza de un pequeho ganado mixto, van a ser muy intensivos en trabajo y utilizar muchos insumos siempre y cuando permitan aumentar el margen bruto por hectárea.

Estos productores, muy integrados al mercado, tienden a especlalizarse en función de los precios de venta de los dislintos productos, pero, al mismo tiempo, conservando un cierlo margen de seguridad -vislos los riesgos agronómicos y de comercialización existentes-, y quedando en los limites impueslos por la debilidad del capital disponible.

\subsection{Diversidad de los pequeños productores campesinos}

Esta diversidad resulla de la diferenciación hislórica de los sistemas de producción campesinos, en un contexto de generalización de intercambios capilalistas, y según por lo menos cuatro delerminantes:

La ublcación geográflca en Zapolitán genera rentas diferenciales y potencialidades distintas de acumulación. Son determinadas más que todo por la calidad de los suelos, el drenaje de invierno, el acceso al sistema de riego y su seguridad (particularidades de la zona 5, proximidad de los canales principales,...).

El nivel de los ingresos externos a la unidad de producción puede intervenir en el nivel de acumulación de la explotación agricola; las fuentes de eslos ingresos extemos son: 
- Miembros de la familia que tienen un empleo permanente (albafiles, empleados, "muchachas",...) o temporal (hijo motorista, jornales en Zapotitán,....).

- El envio de dólares por familiares residenles en los EE.UU. (cada una de cada cualro familias encuestadas, y a veces por más de $500 \$$ anuales).

- La propiedad de una u olra parcela a fuera de Zapotitán (generalmente en una tierra en ladera de Ciudad Arce o Armenia) permite sacar un producto adicional, en granos básicos, o mantener un pequeño rebańo, aprovechando de las complementaridades de los calendarios de trabajo.

La extensión de la propledad genera obviamente niveles distintos de acumulación en el conjunto de estos productores, y cambios en los sistemas de producción correspondientes: abajo de más o menos 2 manzanas, encontramos casí exclusivamente cultivos de granos básicos y hortalizas y un empleo de mano de obra externa muy reducido, para los picos de trabajo. Arriba de este límite - lo que implica un empleo más imporlante de mano de obra externa-, aparece masivamente la crianza de ganado.

Las relaclones de Intercambio a las cuales es sometido el pequefio productor, determinan, a veces fuertemente, las orientaciones de los sistemas de producción. Por ejemplo, frente a un mercado aleatorio y controlado por los intermediarios, la inlegración a una empresa agroindustrial es una seguridad, y puede brindar una cierla renta de mercadeo (pero implica una sumisión a las decisiones de la empresa).

De las multiples siluaciones que surgen sobre la base de estos factores de diferenciación, orientando los sistemas de producción, hemos distinguido 3 casos lípicos, o sublipos: los pequefros productores de hortalizas y granos básicos de menos de 2 manzanas (grupo que incluye la casi totalidad de los campesinos de la zona 1); los agricullorespequen̂os ganaderos, que, con más tierra, buscan mantener un pequeho halo, de manera intensiva; los pequeños productores integrados a una empresa agroindustrial (labacalera, de conservas), y cuyos sistemas de producción tienen una racionalidad un poco distinta.

\subsection{Los slstemas de producción}

Si bien existe una inmensa diversidad de las producciones de los pequefios campesinos (se encuentran por ejemplo flores, yuca, chipilín, labaco,...), los sistemas de producción se caracterizan, más que todo, por rotaciones de granos básicos (maiz, arroz, frijoles) y hortalizas (esencialmente tomates, chile verde, pepino, ejoles),...). Los objetivos de maximizar los ingresos familiares por manzana, incitan estos productores a aprovechar al máximo la tierra, pues a implementar 3 cullivos al año, por 
lo menos en una parte de sus parcelas: las rolaciones más comunes son arroz o maiz en inviemo, seguido de frijoles y hortalizas.

El uso en insumos es globalmente elevado, hasta 6.000 colones por manzana, por año, y en gran parte autolinanciado (con la cosecha precedenle). De hecho, el crédito queda relativamenle restringuido por el banco y llega a veces con retraso, lo que puede ser muy perjuidicial, dadas las exigencias de los cultivos de hortalizas. Además los campesinos tienen sus reservas frente al uso de crédito por lemor de perder su cosecha y sus garantias futuras. Por lo tanto, la escasez de liquidez y los riesgos generados por el uso de la cantidad de insumos "tecnicamente" óptima, explican la elección de un itinerario técnico menos consumidor en insumos que los del capilalista "Iarmer", y que llega a rendimientos un poco más bajos.

Si bien la ganancia de tiempo y la calidad del trabajo justifica la contratación de empresarios de máquinas agrícolas para ciertas operaciones (preparación del suelo), los sistemas van a ser muy intensivos en trabajo (a menudo más de 300 dias de trabajo al año por manzana). Generalmente, las cosechas, las limpias, (azadon) son manuales; encontramos trabajos de mejoramiento de las parcelas plantación de cercos, elc,... o sea, una familia, utilizando toda su fuerza de trabajo disponible, incluyendo los niños, va a invertir trabajo aún para una ganancia adicional reducida.

Por fin cabe subrayar el no control de estos pequeños productores sobre la comercialización de sus productos y su sumisión lotal a los riesgos del mercado y al poder de los intermediarios. Por ejemplo, entre enero y tebrero de 1987, el quintal de pepino pasó de $₫ 39$ a $₫ 4$ al consumidor, y de $₫ 18$ a $₫ 35$ en Zapotitán, cayendo en abril a $₫ 68$ y $₫ 30$ respectivamente 9 . La posesión por el "coyote" de un vehículo, de las cajas o canastas (medio importante de control) y de un capilal financiero que puede prestar (en insumos) definen un poder absolulo que se aplica a través de relaciones individuales y personalizadas, no conlarrestadas, por la ausencia de organización de los pequenos productores al nivel de la comercialización.

Además de estas características generales, es preciso delallar las especilicidades de los 3 sub-tipos identificados y evaluar algunos indicadores económicos.

\subsection{El pequefio productor de granos básicos y hortallzas. (Tipo III-1)}

Fuertemente limitado en el acceso a la lierra (menos de 2 manzanas), dedica loda su propiedad a estos cultivos, tratando, en la optica de maximizar su ingreso familiar, de disminuir los picos de trabajo, que los 
Cuadro No. 1

Comparación de los calendaros de trabajo de dos sistemas

de producclón: única rolaclón (arroz-frljoles-tomates)

$y$ dos rotaciones (arroz-frljol-tomate) más

(arroz-chlle-elolet) sobre una misma área

\begin{tabular}{|c|c|c|c|c|c|c|c|c|c|c|c|c|c|c|}
\hline mes & $\bullet$ & $f$ & $\mathbf{m}$ & $\mathbf{a}$ & $\mathrm{m}$ & 11 & I & a & 8 & 0 & $\mathbf{n}$ & d & (I) & (II) \\
\hline $\begin{array}{l}\text { Dlas de traba- } \\
\text { jo pr manzana. }\end{array}$ & & & & & & & & & & & & & & \\
\hline $\begin{array}{l}\text { única rotación } \\
\text { A-F-T }\end{array}$ & 60 & 32 & 23 & 63 & $\mid 18$ & 10 & 6 & 4 & 40 & 14 & 14 & 18 & $\begin{array}{l}230 / \\
260\end{array}$ & $\begin{array}{l}50 / \\
80\end{array}$ \\
\hline $\begin{array}{l}\text { dos rolaciones } \\
\text { A-F-T A-C-E }\end{array}$ & 60 & 32 & 21 & $37 \mid$ & 18 & 10 & 6 & 4 & 47 & 23 & 16 & 35 & $\begin{array}{l}250 / \\
280\end{array}$ & $\begin{array}{l}20 / \\
50\end{array}$ \\
\hline
\end{tabular}

(i): dles de trabajo realizado por miembros dela familia

(ii): dlas de trabajo electuados por jornaleros.

- cultivo de malz para producir elotes para su venta en el mercado.

Fuente: encuestas.

obligarian a emplear jornaleros, y de asegurarse al máximo contra los riesgos agronómicos o económicos. Por eso, la diversíficación de los cultivos especialmente de hortalizas y las siembras escalonadas son muy frecuentes (ver el cuadro No. 1).

La conlratación de jomaleros siempre es necesaria, aún para solamente una manzana, excepto si la farnilia dispone de mucha mano de obra por lo menos lemporalmente (hijos que regresan para el transplante o la cosecha). Este análisis trecuencial del trabajo muestra además que la época de relativo subempleo (inviemo) permite al campesino dedicarse a una parcela de granos básicos que puede tener fuera de Zapotitán.

Para estos pequenos productores, el valor agregado creado por manzana y por ano es uno de los más altos del distrito, entre 6.000 y 9.000 colones del cual el $90-95 \%$ esla constituido por el ingreso tamiliar: una familia campesina de la zona 1 (1 ha), que logra implementar los tres cultivos, sin "accidentes" agronómicos, puede sacar un ingreso que anda por los $8.000-9.000$ colones anuales.

\subsection{El agricultor-pequefio ganadero (Tipo III-2)}

Con una propiedad más importante, enlre 2 y 7 manzanas, combina los cultivos de granos básicos y hortalizas, que constiluyen siempre su 
principal fuente de ingreso, y la crianza de un pequefio rebaño bovino mixto. Distintos elementos justifican esta elección productiva: tener bueyes aumenta la productividad del Irabajo en los sistemas de cultivos y proporciona un ingreso adicional, al poder proponer sus servicios a otras explotaciones. Se crian terneros de los cuales unos son vendidos (los demás renovan el halo), y a la vez, producen leche para el autoconsumo y la venta. Además, el ganado constituye una forma de ahorro relativamente seguro, "monetarizable" en cualquier momento; pero, permite más que todo emplear plenamente la mano de obra lamiliar cuando en las parcelas de horlalizas ya se emplea mucha mano de obra externa durante los picos de trabajo. Efectivamente a partir de 2-3 manzanas cultivadas en granos básicos y hortalizas, la manzana adicional requiere la contratación de por lo menos 250 jornales, reduciendo el ingreso tamiliar a 4.0006.000 colones en esla manzana; en comparación, esla manzana puesta en pastos, con hasta 5-6 cabezas mayores, brinda el mismo nivel de Ingresos, sin requerir empleos externos adicionales (por la regularidad y la debilidad de la demanda en trabajo, realizable en parte por los ninos) y con todo los demás intereses ya expueslos.

Los requerimientos multiples y las exigencias de resistencia, como la falla relativa de capilal linanciero, hacen que las razas generalmente sean Brahman, cruzadas con criollas 0 , cruzadas con lecheras: entonces, la producción de leche no sobrepasa las 5-6 bolellas diarias por vaca.

La carga por área de paslos es muy elevada (hasla 4 vacas por manzana), lo que es posible gracias al cullivo de pastos de corte, la compra de concentrados o de torrajes verdes (cana, hojas del malz de elote), el uso de los residuos de las cosechas: existe realmente una asociación cultivos-ganadería al realizarse - además del uso de los bueyes para la tracción-, transferencias de fertilidad (recuperación del estiercol en el establo y/o estancia de los animales en las parcelas) y cullivos de forrajes.

\subsection{Los pequefios productores Integrados a una empresa agrolndustrial. (Tipo III-3)}

Representan un gnupo distinto: el contrato firmado con la empresa tabacalera o de conservas-, tija antes del inicio de los cultivos, los precios de venta en función de la calidad de los productos y le garantiza al productor una asistencia técnica importante (cada semana para el labaco) $y$ el abastecimiento en insumos. En realidad, la empresa determina y controla la casi totalidad del itinerario técnico, imponiendo siempre una cantidad de insumos superiores a la que maximizarla el ingreso de la familia. En el caso de la producción de tabaco, se imponen intervenciones, como la destrucción de rebrotes (para prevenir la extensión de las plagas) sancionando su no cumplimiento con multas altas ( $₫ 500$ ). Además, los precios diferenciados en función de la calidad hacen asumir una 
parte de los riesgos sobre el produclor.

No obstante, el interés del productor reside en una seguridad más importante en el abastecimienlo de los insumos (son relativamente específicos para el tabaco, como el abono 13-0-44), en el acceso a la asesoria técnica y en la comercialización. En cuanto a la producción de pepinos, la integración a la empresa enlatadora corresponde a una cierta renta de siluación al productor, ya que los precios de venta son casi de $50-60 \%$ más altos que los que olrecen los coyotes (poniendo más insumos que el óptimo económico, obtienen lodavia ingresos por manzana superiores a los de explolaciones no inlegradas). Para la empresa, que escoge sus productores, la garantía de una calidad de "exportación" justitica estos precios de compra al productor.

\subsection{Conclusión}

Dentro de la diversidad de los campesinos intensivos, se encuentran dinámicas de acumulación, especialmente para los que tienen más de 2 manzanas; pero muchos productores de la zona del pantano logran solamente reproducir su familia.

El principal factor limitante reside en la comercialización de las hortalizas: parece urgente implementar una política de precios adecuados (precio minimo tijado, mantenido por un control de las importaciones), cuyo éxito depende de la organización previa de los pequenos productores en cooperativas o grupos de presión.

Subrayemos la importancia de la interdependencia entre el acceso al crédito y el control de la comercialización: la obligación de vender al intermediario usurero en el sistema actual, impone la toma en cuenta de estos dos elementos juntos para proponer soluciones.

\section{Los campesinos sin tlerra}

\subsection{Lóglca de reproducclón}

Se distingue, en el seno de las unidades de producción del distrito de Zapotitán, una lógica de reproducción que hemos llamado "inmediatista", o más bien de "sobrevivencia": se trata de familias que no tienen ninguna seguridad en el acceso a la tierra, a los medios de producción, al linanciamienlo,... y que, no obstante, cultivan un área muy reducida, desde 1 o 2 lareas hasla una manzana, bajo diversas relaciones de tenencia (alquiler de parcela, colonato, ocupación de facto de un terreno estatal, etc).

Históricamente, estas familias provienen ya sea de pequenos productores de la región $0,-y$ es ahora lo más importante-, son desplazados de guerra radicados en Zapotitán, pero: 
- los distintos miembros de la familia se emplean temporalmente en las fincas del distrito (zatra, trasplante y cosecha de hortalizas,...),

- estas unidades de producción no son estables, ya que el acceso a la tierra es muy aleatorio y se define cada año o ciclo de cultivo. Esta inseguridad tolal, agudizada por los efectos del decreto 207, forlalece el poder del propietario e implica más que antes recurrir a las relaciones personales (comfianza) para conseguir la parcela.

\subsection{Sistemas de producclón}

En general, los sistemas de producción están orientados en primer lugar a la producción de granos básicos (maiz y frijoles) para el autoconsumo, completada eventualmente por hortalizas. Los itinerarios lécnicos correspondientes utilizan pocos insumos pero mucho trabajo familiar: la casi inexistencia de liquidez financiera (constituida por la remuneración del trabajo de jornalero), la imposibilidad de conseguir créditos $\longrightarrow$ en condiciones sumamente destavorables con los coyoles-, constituyen el principal factor limitando el nivel de los rendimientos.

Encontramos 203 variaciones en estos sistemas de producción, que están determinadas esencialmente por el tipo de acceso a la tierra:

- Los colonos o cuidanderos consiguen un pedazo de lierra a cambio de servicios de vigilancia o de mantenimiento en la finca en donde están ubicados. Estas unidades de producción incluidas en otras más grandes, pueden aprovechar sus relaciones con el duefio para disminuir algunos costos (insumos, crédilo,...), y representan siluaciones más estables que el alquiler o el uso de facto.

- Los pequenos arrendatarios alquilan para un ciclo (4-5 meses) una parcela a un pequeńo propietario que no puede cultivarla. Estan más integrados al mercado, produciendo hortalizas o frijoles para la venta, 10 que les permile pagar el alquiler (alrededor de 300 colones la media manzana para 5 meses). Los cálculos muestran que muy a menudo, la remuneración del trabajo en estas parcelas es apenas superior a la del jornalero (especialmente por los bajos niveles de rendimientos). Sin embargo, el trabajo en la tierra alquilada no entra necesariamente en competencia con un trabajo fuera (a menudo aleatorio). El conocimiento técnico de los cullivos de hortalizas ha sido adquirido anteriormente, al emplearse en otras fincas de Zapotilán.

- Las "microunidades" de producción de los obreros agrícolas se encuentran en las orillas de las calles o de los ríos, en terreno del eslado, - evenlualmente prestado: alrededor de las casas de adobe y paja, el "solar" esta sembrado con guineos, maiz, ayote, maicillo. El uso de desechos domésticos (cenizas, basura,...) permite la reproducción de la 
fertilidad. Esta producción exclusivamente de autoconsumo representa apenas el $10 \%$ del ingreso anual total de la familia.

\subsection{Conclusiones}

Los campesinos sin lierra, que en realidad constituyen una parte de las reservas en mano de obra del distrito de Zapotitán consiguen entre 3.000 y 5.000 colones de ingresos lamiliares anuales de los cuales hasta $75 \%$ pueden provenir de la producción en la parcela. Este nivel de ingreso no permite ni siquiera la reproducción de la tamilia ya que muchas de ellas padecen de desnutrición (ver el cuadro No. 2). Esta imposibilidad de acumular impide el pasar de este tipo al de tipo de "campesino intensivo de Zapotitán". Las allernativas son pocas: estatuto de cuidandero que sea más estable, o búsqueda de otras actividades fuera de Zapotitán, en San Salvador o en los Eslados Unidos.

Cuadro No. 2

Balance de entradas-salldas de un pequefio arrendatarto

(0.5 manzana) para el año 1987.

\begin{tabular}{|c|c|c|c|}
\hline \multicolumn{2}{|l|}{$\begin{array}{c}\text { Entradas } \\
\text { (colones 1987) } \\
\end{array}$} & \multicolumn{2}{|c|}{ Salldas } \\
\hline \multicolumn{2}{|c|}{ 1. Producción parcela: $\quad 3800$} & \multirow{3}{*}{$\begin{array}{l}\text { Autoconsumo } \\
\text { Insumos }\end{array}$} & \multirow{3}{*}{$\begin{array}{l}1800 \\
900\end{array}$} \\
\hline \multirow{2}{*}{$\begin{array}{l}\text { - maiz }(900 \mathrm{~kg}) \\
\text {-trijoles }(200 \mathrm{~kg}) \\
\text {-tomates ( } 250 \text { cajas) }\end{array}$} & \multirow{2}{*}{$\begin{array}{r}800 \\
1000 \\
2000\end{array}$} & & \\
\hline & & & \\
\hline 2. Trabajo de jomalero & 2000 & Alquiler & 600 \\
\hline (200 dlas) & & Compras para & consumo \\
\hline Tolal entradas & 5800 & $\begin{array}{l}\text { - arroz } \\
\text {-aceite }\end{array}$ & $\begin{array}{l}360 \\
210\end{array}$ \\
\hline $\begin{array}{l}\text { Ingreso familiar } \\
\text { (Total entradas- }\end{array}$ & 4300 & $\begin{array}{l}\text {-jabón } \\
\text {-otros }\end{array}$ & $\begin{array}{r}280 \\
1150\end{array}$ \\
\hline & & Total salidas & 5800 \\
\hline
\end{tabular}

Fuente: encuestas. 


\section{Conclusión de la tipologla}

tesis:

A partir de esta tipología, podernos sacar distintos elementos de sin-

5.1. El esquema No. 1 nos permite visualizar la dinámica de formación de los dislintos tipos y tralar de prever las evoluciones fuluras:

Todos los pequenos productores campesinos (Tipo II) provienen de la redistribución hecha por el Estado (1935-45, laguna en 1969, decreto 207). A partir de esta base, actores exteriores (burguesia urbana o empresas por ejemplo) han constiluido nuevas unidades de producción en dislintas ocasiones pero más que todo desde el inicio del proyecto, to que ha provocado el surgimiento de muchos tipos distintos.

Hay pocas posibilidades de movilidad de un lipo al otro: imposibilidad para los campesinos sin tierra de pasar a los tipos III (a menos de una nueva redistribución del Estado); diferenciación únicamenle interna de los tipos III, que de nuevo venden su parcela a actores externos $\left(\mathrm{II}_{3}\right)$, supervivencia de la lógica rentisla más que lodo por razones de seguridad o especulativas, consolidación de las unidades capitalistas.

La tendencia general es entonces una expansión lenla de las unidades capilalistas en perjuicio de los tipos III ("descampesinización") o de las fincas de cana, las condiciones generales siendo reunidas para atraer el capital. Pero se orienta hacia unidades relativamente pequehas (5-15 ha), excepto para las lincas lecheras.

5.2. Las comparaciones entre los distintos ralios económicos de los tipos identilicados, especialmente el valor agregado y su distribución (ver el cuadro No. 3), nos permile ahora definir concretamenle cuales son las unidades de producción que responden a los objetivos del proyecto (maximización del valor agregado y del empleo por manzana). En esle sentido, los pequenos campesinos intensivos (III), a pesar de una serie de limilaciones fuertes (comercialización, ...) y de una variabilidad importante de sus resultados económicos, cumplen tolalmente con esta meta, asl como las fincas lecheras (más valor agregado pero menos trabajo por manzana) y en una escala menor, las pequenas propiedades de ubanos y los farmers.

No obstante, hemos visto que la evolución actual del sistema agrario privilegia unicamenle el desarrollo de las unidades capitalistas. Parece entonces Justificada la construcción de una polftica agricola que, especialmente en Zapotitán, organizaria las condiciones socio-económicas necesarias para favorecer la acumulación de los campesinos intensivos, y garantizar su permanencia. Además, la repartición del valor agregado debe ser un punto de análisis, de juicio, en relación con el proyecto socioeconómico global: en el caso de un proyeclo que busca la satisfacción 
de las necesidades populares, privilegiando mecanismos de redistribución directa, prevalecen una vez más los campesinos intensivos.

5.3. El estudio de los distintos lipos nos enseha, ánles que todo, la importancia de las relaciones con el seclor "río abajo": integración fuerte de distinlos tipos con empresas agroindusiriales privadas (cana, leche, pequenos productores $\mathrm{II}_{3}$ ), control directo de la comercialización (tipo $\mathrm{I}_{2}$ ). $y$, más que todo sumisión total al poder de los intermediarios $\left(\mathrm{II}_{3}, \mathrm{II}_{1}, \mathrm{II}_{2}\right.$, IV). Este campo de intervención debe ser priorizado por las politicas gubernamenlales, componenles indispensables para el apoyo a los pequenos productores intensivos: promoción y respaldo a la organlzación de estos productores para la recolección de las hortalizas y de la teche, etc.

5.4. Los intermediarios usureros, la administración central del distrito -que, además de los inlereses propios de sus funcionarios, refleja las decisiones tomadas "arriba" (MAG e inslituciones extranjeras)-, las empresas "rlo arriba"y "río abajo" animadas por una Kogica comercial, concentran un poder importante e influyente en las decisiones de los agricultores. En realidad, ellos "viven" del proyecto y se encuentran dentro de sus principales beneficiarios.

Los origenes diversos, y la fuerte heterogeneldad de los productores son elementos que limitan sus posibilidades de organtzación, en un contexio socio-politico nacional relativamemle destavorable. Algunos lideres campesinos tradiclonales (cerca del tipo $\mathrm{III}_{2}$ ) thenen una cierta legitimidad para las actividades comunitarias de los "antlguos" caserios y para la administración del. riego en la zona 1; pero, los medianos y grandes productores (I y II), que tienen relaciones con eslucluras de poder externas (grupos gremiales, empresas, ejérclto, goblerno....) polarizan el poder real en la zona y tratan de controlar las eventuales organizaciones de productores.

Asl, ellos constituyeron, con algunos campesinos de Zapotttán, la "Casa de los Agricultores de Zapotitán", que querla que pasara "la admlnistración del distrito a las manos de los agricultores". Pero esta organización, en donde los volos se hacian en función de la superticle poseida, fue disuella por el gobierno (inicio 1987), después de la difusión de criticas violentas en contra de la administración del MAG.

No obstante, bajo las presiones de Instituclones financleras extemas (GTZ), se ha constituido en 1987 la Asociación General de Agricultores de Zapotitán, AGRIDERZA, (eso era una condición para olorgar un relinanciamiento del proyecto). Esta asociación integra más pequefros productores y quiere sustitulir, a medlano plazo, a la administración del MAG. Pero, no parece tener, hasla ahora, una real posibllidad de accion, al no querer volver a discutir la estructura agrarla de la zona, base de la 
distribución actual del poder económico y polílico.

\section{Conclusión general}

Si bien el drenaje de la cuenca de Zapotitán y la consirucción de infraestructura viales han tenido indiscutiblemente consecuencias positivas, concluimos en el fracaso global (quisaz con la excepción de la zona 1) del proyecto iniciado en 1971, visios sus objetivos iniciales, la subutilización actual de los recursos existentes y la debil acumulación de la mayoría de los productores.

Las explicaciones del fracaso pueden resumirse en 5 puntos:

1. Hizo falta la existencia de un diagnóstico agro-económico profundlzado, que hubiese podido prever el desarrollo de la cańa de azúcar (por un estudio de las estralegias de los grandes propietarios), el incremento de la dependencia frente a los coyoles (por un análisis delallado de los sislemas de producción ya existentes y de las estructuras de crédito y de comercialización), el fallo técnico de los pozos, y que hubiese estudiado el antiguo sistema de riego, ciertamente más "apropiado" y administrable, como lo demuestra la organización actual de la zona 1.

2. El Iracaso se debe también a la elecclón tecnológlca Iniclal en sl y a la del modo de gestión del agua. El cambio técnico realizado luvo un coslo alto; además, es fragil y sometido a "riesgos económicos" (repuestos importados y ahora obsoletos, abastecimiento en energía eléctrica poco seguro), y dio demasiado peso a la extracción de agua subterranea. La administración centralizada del agua genera desvíos burocrálicos que compromelen la eficacia del sistema de riego, y un precio del acceso al agua alto. Además, no se intento ninguna gestión global de los recursos hídricos que hubiera tomado en cuenta los agricultores ubicados a fuera del distrito (en rio arriba) y las empresas que usan y contaminan el agua.

3. Al no transformar las estructuras agrarlas, no se resolvió la profunda contradicción entre los objetivos iniciales del proyecto y el de los grandes propietarios. Verros ahora que los pequenos campesinos intensivos, cuya lógica de reproducción implica el cumplimiento de los objetivos asignados al proyeclo (interés de este tipo de acuerdo con el interés "nacional") son "eliminados", mientras que los duefios de fincas de cana pueden agradecer el proyeclo por haber incrementado fuertemente el valor monelario de sus tierras.

4. No hubo, de parte del Estado, políticas económicas y soclales para acompanar este proyecto puramente técnlco:

- Las instituciones linancieras (estatales o privadas) no dieron una 
respuesta adaptada a la importante y específica demanda de crédito generada por el proyecto.

- El único intento de organización de la comercialización de las hortalizas producidas en Zapolitán fue el "Mercado de Zapolitán", impulsado por el MAG y por la cooperativa de crédito; tiene 10 años de no funcionar.

- La investigación agronómica salvadoreña ofreció pocas variedades de hortalizas adapladas a las caracteristicas ecológicas de la zona.

5. Por tin, nos parece importante insistir en las palabras de Fernand Braudel: "Un cambio tecnológico vale por el movimiento social que lo sostiene". El proyecto de Riego de Zapolitán, en su concepción misma y en su administración, corresponde a un proyecto típico de "arriba hasta abajo", que no ha generado las condiciones para su adopción por los agricultores, o más bien por la gran mayoria de ellos que sin embargo cumple con los objetivos económicos asignados inicialmente al proyeclo. La definición del proyecto, y su fracaso, resulta de un compromiso, de acuerdo a las relaciones de fuerza existentes antes de la creación del distrito, entre el estado (y sus esferas tecnocráticas), la empresa privada agroindustrial y los grandes propielarios ausentistas. Este "movimiento social" que excluye en realidad a las mayorias campesinas, no ha podido llevar a un óptimo de desarrollo el valle de Zapotitán.

\section{BIBLIOGRAFIA}

Barberena Santiago: "Historia de El Salvador" -Tomo L- Ministerio de Educación, San Salvador, 1977.

Barón Castro Rodolio: "La población de EI Salvador UCÁ Editores, San Salvador, 1978.

Browning David: "El Salvador, la tierra y el hombre". Ministerio de la Cultura y Comunicaciónes, San Salvador, 1987.

Cardona Lazon Antonio: "Monografias de los deparlamentos de Sonsonate y La Liberlad", San Salvador, 1938.

Dufumier Marc: "El Salvador, la question agraide". Problems d'Amérique Latine No. $\mathbf{4 8 3 0}$ Documentación Francaise, Paris, 1987.

Gronimij-Debilt: "Project for the agricultural development of the Valle of Zapotitán", 1961.

Gutiérrez y Ulloa Antonio: "La provincia de San Salvador, Reyno de Guatemala". Colección Historica, Ministerio de Educación, San Salvador, 1962.

IICA-MAG: "Perfil IICA del Distrito de Zapotitán". Publicaciones Miscelaneas No. 373, 1982.

Larde y Larin Jorge: "El Salvador, Descripción de sus pueblos, villas y ciudades". Ediciones Ministerio de la Cultura, 1958.

MAG: "Investigación socio-económica, Distrito de Riego y Avenamiento No. 1, Zapotitán", Dirección General de Obras de Riego y Renaje, 1971.

Mejlvar Ralael: "Acumulación originaria y desarrollo del capilalismo en El Salvador", EDUCA, San Salvador, 1980.

Mindinra-Cierra: "Historia agraria de las Nuevas Segovias", Managua, 1984.

Montelorte Toledo Mario: "Centro América. Subdesarrollo y dependencia". Vol. I. UNAM, México, 1972. 
Montes Santiago: "Etnohistoria de El Salvador", tomo I. Ministerio de Educación, San Salvador, 1977.

PNUD-BID: "Proyecto de Zapotilán": Proyecto PNUD-BID No. RLA 71118, Inlorme del Comité Nacional en El Salvador, 1974.

Quiroga Eduardo: "La transformación de la agrieultura de subsistencia mediante el riego de El Salvador". in América Indlgena, Vol. XL No. 3. 1980.

Rubio Sánchez Manuel: "Historia del añil o xiquile en Centro América" Tomo 2, Ministerio de Educación, San Salvador, 1976.

Solano Hernández J. H.: "Evaluación socioeconómica del Distrilo de riego y avenamiento No. 1, Zapotitán". Universidad de El Salvador, Facultad de C.C.E.E., nov. 1979 (lesis).

Whaite Alistaer: "El Salvador'. UCA Edilores, San Salvador, 1983.

\section{NOTAS:}

1. Formalmente divididas entre miembros de la misma familia, para sortear la ley de creación del distrito, que fija a $\mathbf{5 0}$ hectáreas del limite superior de las explotaciones beneficiarias.

2. En un contexto de escasez de agua más que lodo subterránea (solo 5 pozos sobre 20 funcionan), los casos de corrupción se han multiplicado: para estar seguro de conseguir un tumo de agua en una lecha dada, los agricultores a menudo tienen que pagar mordida al canalero.

3. Por analogla con los "open-lields", los paisajes de grandes parcelas abiertas.

4. Por ejemplo el proyecto de reforma agraria de la U.S.A.I.D. (1967), que proponla distribuir 420.000 manzanas en la planicie costera y que fue totalmente rechazado: ver anexos del informe linal, lbid.

5. Por 3 consultores sucosivos: Grontzij (Palses Bajos), Harza y Tahal (Israel).

6. Al cual se añaden $\theta$ millones de refinamiento; linanciamiento norteamericano y realización técrica israell es una combinación corriente.

7. Lo que demuestra que no trata de una lógica capitalista, visto que en otros sectores la asa de ganancia del capital total inmovilizado alcanza los $12 \%$ anuales.

8. Actualmente, por lo menos 150.000 colones por 5 manzanas. 
Esquema No. 1

Genesis y evolución de los distintos tipos de productores agrícolas del distrito de Zapolltán




Cuadro No. 3

Componentes "promedlos" de los valores agregados por manzana realizados

por los dlstintostipos de productores agricolas de Zapotitán

(según encuestas y cálculos propios). (ver la correspondencia entre los números y los lipos en la parte III).

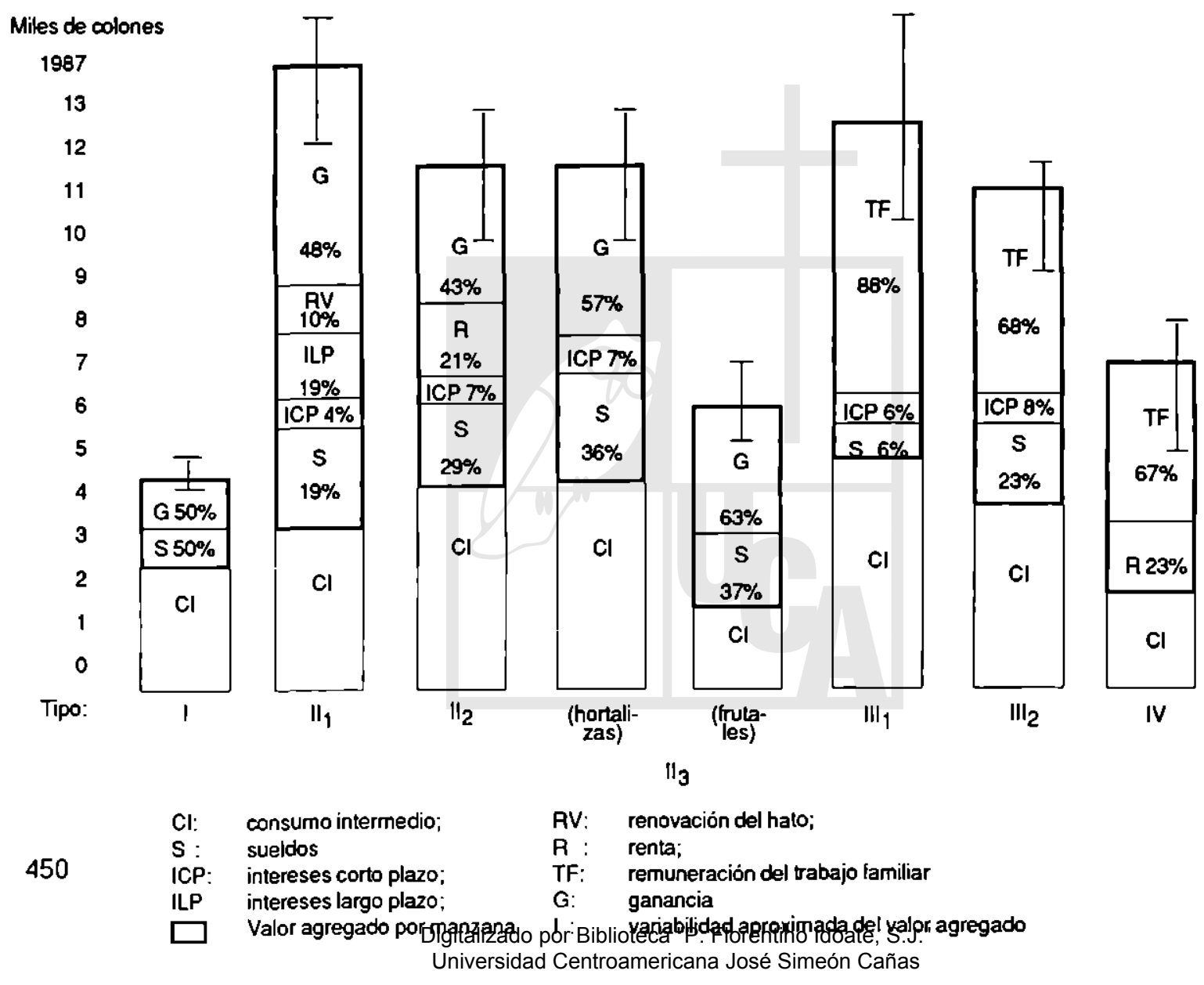


Características (en trabajo y valor agregado) y peso relatlvo de los distintos tipos. Elaborado en base a encuestas proplas y "cruce" de variables estadisticas exlstentes

\begin{tabular}{|c|c|c|c|c|c|c|c|c|}
\hline Tipo & I & $\mathrm{II}_{1}$ & $\|_{2}$ & $\begin{array}{c}\mathrm{I}_{3} \\
\text { Hortalizas }\end{array}$ & Frutas & $\mathrm{III}_{1}$ & $\mathrm{III}_{2}$ & IV \\
\hline $\begin{array}{l}1 \text { Valor agregado } \\
\text { por manzana } \\
\text { (colones 1987) }\end{array}$ & $2000-2200$ & $9000-11000$ & $6000-8000$ & $6000-8000$ & $3500-4500$ & $6000-9000$ & $6000-7000$ & $3000-5000$ \\
\hline $\begin{array}{l}2 \text { días-hombres } \\
\text { de lrabajo por } \\
\text { manzana (pro- } \\
\text { medio) }\end{array}$ & 80 & i50 & 250 & 250 & 150 & 320 & 250 & 300 \\
\hline $\begin{array}{l}\text { Productividad" } \\
\text { del trabajo } \\
\text { (colones por día) } \\
(1 / 2)\end{array}$ & 25 & 70 & 28 & 28 & 27 & 25 & 26 & 15 \\
\hline $\begin{array}{l}\text { Peso relativo den- } \\
\text { tro de las unidades } \\
\text { de producción }\end{array}$ & $1 \%$ & $0.5 \%$ & $2-3 \%$ & $\theta-10 \%$ & $0.5 \%$ & $60-65 \%$ & $12-17 \%$ & $10-12 \%$ \\
\hline $\begin{array}{l}\text { Peso relativo en } \\
\text { el área agrícola }\end{array}$ & $22 \%$ & $8 \%$ & $12-15 \%$ & $17-20 \%$ & $1 \%$ & $20-22 \%$ & $10-15 \%$ & $1-2 \%$ \\
\hline
\end{tabular}

- A comparar con la remuneración monetaria del trabajo agrícola: $€$ 10-12. 